\title{
IMPACT OF GENDER DIVERSITY AND LEADERSHIP ON ORGANISATIONAL INTEGRITY IN PAKISTANI INDUSTRIAL SECTOR Muhammad Arif $^{1^{*}}$, Panteha Farmanesh ${ }^{2}$ \\ ${ }^{1 *} \mathrm{PhD}$ Doctor, International Business Management, Girne American University North Cyprus; ${ }^{2} \mathrm{Head}$ of International Business Management, Girne American University North Cyprus. Email: ${ }^{1 *}$ rising_620@yahoo.com, ${ }^{2}$ pantehafarmanesh@ gau.edu.tr
} Article History: Received on $20^{\text {th }}$ February 2020, Revised on $25^{\text {th }}$ July 2020, Published on $20^{\text {th }}$ August 2020

\begin{abstract}
Purpose of the study: The main purpose of this study is to analyse the impact of gender diversity on organisational integrity in the context of Pakistani industrial sector. This study also investigates about the influences of female leaders on the association between diversity and organisational integrity and evaluates the effect of work place diversity on increase in organisational performance.

Methodology: This study involves mediating and moderating variables along with independent and dependent variables, therefore researcher in this study has utilised Structural equation model (SEM) and Meta Regression Analysis (MRA) for achieving the main objectives of this research. The researcher has followed the positivism research philosophy as well as deductive research approach. In this study, researcher has followed quantitative research design to attain the key objectives of this study.

Main Findings: From the results of study, it can be suggested that employers in Pakistan should diversify their workforce and also look to hire female candidates for the same position as male candidates since it would increase the work efficiency and integrity within an organisation as women tend to work more or equally passionately in their respective fields similar to men.

Applications of this study: So, the study of impact of gender diversity on organisational integrity in the context of Pakistani industrial sector is not only useful for IT department but also useful for all organisational where gender diversity exists.

Novelty/Originality of this study: Finally, it is important to clarify that one of the research gap that has been identified is the difference in wages between the male and the female employees. The difference in the pay scale between the two genders is considered to be a sophisticated gap that the research can deliberately overcome.
\end{abstract}

Keywords: Gender Diversity, Organisational Integrity, Industrial Sector, Pakistan, Cultural Mediation, Workplace Abuse.

\section{INTRODUCTION}

Diversity in the organisation is considered to be the variety of workforce that exists in the organisation (Idrees, Abbasi \& Waqas, 2013). It is important to suggest that diversity in the organisation is considered to be of two types which are; Gender and Cultural diversity (Tahir et al., 2014). In accordance to the study that has been conducted by Wahab and Jaafar (2018) it is important to highlight that the role of diversity in an organisation is most likely be considered to improve the performance. The reason being is that it leads to the generation of new ideas and helps organisation to achieve their desired goals and objectives. As per the study that has been conducted by Rojas (2018) though it may be difficult for the managers to be easily gain control of diversified workforce but when diversity exists in an organisation it can lead to great advantages for the organisation.

The research has specifically been conducted in the perspective of Pakistan where its focus has been made towards the industrial sector of the country (Abbas, 2014). In light of the study that has been conducted by Khan et al (2012) the problem that has been highlighted is that mostly organisations in Pakistan are considered to have a workforce which consists of mostly males. It creates a reputation of some organisations to be male dominated which leads to the point that the number of females are less (Sarwar, and Abbasi 2013). Another problem that has been identified is the lack of literature which exists that is related to the topic of the study for which this research has been conducted in order to present a detailed information regarding the organisational integrity which is likely going to be impacted by the diversity in the industrial sector of Pakistan (Connon \& Corneliussen, 2016).

Another problem that has been highlighted in the study that has been conducted by Ashraf (2017) is the lack of integrity in the Pakistani organisations which are understood to be a major problem. It has relatively led to the rise of corruption and unethical practices which has considerable lowered the performance of the organisation. Often in a male dominated organisation the female gender is not treated much well in Pakistan and can be subjected to many issues. This research has tried to identify the numerous issues that Pakistani women have to go through in a male dominated workplace. It is also important to suggest that there is a lack of innovation in the industrial sector which is a result due to the lack of diversity which dismisses the concept of innovation. 


\section{AIMS AND OBJECTIVES}

The main aim of this study is associated with analysing the impact of diversity on organisational integrity in the context of Pakistani industrial sector. To incorporate all the important aspects related to the research topic, it is important to break down the argument in a manner that helps the researcher to accomplish key aim of this research. Therefore, the following objectives are developed to achieve the main goal of this study:

$>$ To find out whether an increased gender (w.r.t women) representation in the Pakistani Industry lead to an improvement in organisational integrity.

$>$ To investigate how the incidence of female leaders influences the association between diversity and organisational integrity.

$>$ To know whether work place diversity has an important effect on increase in organisational performance.

\section{LITERATURE REVIEW}

This chapter is the review of literature on the impact of diversity over the organisational integrity. The main focus of the study over analysing the impact in the Pakistani Industrial sector whereas the researches that have been conducted all over the world is included in it. Diversity is considered to be one of the major issues for the human resource management in any organisation (Rice, 2015). It has many impacts over different operations of the organisation and affects the integrity of the organisation. The main operations of the company in which the production, marketing and corporate culture are involved are affected by the diversity and the way by which the diversity is perceived world-wide (Anjorin and Jansari, 2018). Sexual violence is considered as any sexual act that is done sexually in terms of violence (Barger, et al. 2018).

The factors that affect the integrity of the organisation are discussed along with the impact of diversity over the organisational integrity. Furthermore, this chapter also includes the impact of increased gender representation of females over the integrity of the organisation and the role of gender in order to influence the links among the diversity and the organisational integrity (Mak, 2017). There is a detail of impact of workplace diversity in order to enhance the performance of the organisation in the light of different studies that have been conducted by previous researchers. The organisational integrity in the industrial sector of Pakistan is also discussed in this chapter along with the gap that is bridged by this study.

There are several theories that are related to the diversity management and organisational integrity, the theory that is be applied on this study is social learning theory which is considered as the process of learning and linked with the social behaviour. There are several new behaviours that are proposed in this theory that are acquired by the imitation and observation. As per this theory it is analysed that the people engage with some particular activity due to their association with the people engaged in that activity. Another theory that is applied on the study is social exchange theory that is psychological and sociological theory in which the interactions among two parties are analysed by implementing the cost benefit analysis for the determination of risks as well as benefits (Cropanzano, et al. 2017). These theories would help to determine impact of diversity on organisational integrity. In the light of the research by Barrett, (2018), integrity is known as the base, depending on which the employees develop interpersonal relationships that are mainly based over the trust. Such employees having integrity values the relationship with each other in the context of organisation, they also value the relationship with the stakeholders and customers.

\section{Diversity}

It is analysed that the main factor of the concept of diversity is respect and acceptance. Diversity is defined as understanding and accepting the uniqueness in every individual by recognising the differences of every individual. This difference can be on the basis of ethnicity, gender, sexual orientation, age, religious or political beliefs, physical abilities, socio-economic status or on the other ideologies. Diversity have a direct impact on organisational performance because it provides an organisation with a wider and different perspective (Ellis, \& Keys, 2015). For example, when similar kind of employees are working in an organisation let say all are males or people belong to certain ethnicity, culture or religion etcetera, they provide organisation with limited information which is according to their own beliefs, experiences, viewpoints and opinions, in short, they provide a limited perspective.

\section{Organisational Integrity}

Trust is considered as the main factor of organisational integrity as it is fundamental for the high performance in the team as well as high engagement in the organisation. The integrity in the organisation is based over the trust yet a lot of hard work is required in order to establish the organisational integrity. The integrity in the organisation should be established by the senior leaders of the organisation as a role model that juniors should follow. Organisational integrity can be enforced by holding the managers in the account as there is a need of reinforcement with the help of reward schemes and recognition. Organisational integrity can be demolished by the error of judgment as well as it can be redeemed by the apology and acknowledgement 
(Gardiner, Parry and Robinson, 2017). Such organisations that takes too long to trust everything as they have low level of trust, lacks at the resources as they have consumed a lot of time in building trust with each other.

\section{Gender Supervisor}

Gender diversity management is considered to be very important for improving the operations of the organisation as it is very similar to diversity management. The only concept that leads the organisation towards profits is that the best talent should be promoted irrespective of gender (Kelsey, 2015). Gender diversity management is very important for the creation and maintenance of such environment in the organisation that attracts, retain and provide equal opportunities to the men and women (Lo ,2016). For the successful development of gender diversity management, there should be creation of equal opportunities for both male and female (Kim and Mullins, 2016). It is analysed that women are considered as the minority gender in the labour market so there are several activities that are being performed in order to promote the women empowerment. Female supervisors affect the diversity in an organisation and promote the organisational integrity as they try to create the level of trust among their employees (Van Wagoner, et al. 2019).

\section{Workplace Abuse}

Workplace abuse is considered as the stubborn pattern in which other people are mistreated in the workplace physically or emotionally. The tactics that are including in workplace abuse are physical, psychological, verbal and nonverbal abuse as well as humiliation (Hong, 2016). This is considered as the part of workplace aggression and is very difficult to manage. Workplace abuse usually operates in the established policies and rules that are set in the society and the organisation. It usually reported in such workplaces that have diverse workforce and have negative impacts over the organisational integrity.

\section{Impact of diversity on organisational integrity}

There are several benefits that can be gained by the employers, employees and business leaders by organisational integrity. The main features of organisational integrity are moral judgment, character and trust. Such employees that shows integrity in the workplace understands the right from wrong as well as they practice this in their daily lives (Rizwan et al. ,2016) It is considered to be beneficial for the environment of business as the foundation for the successful relations of the business is trustworthiness. It is very easy to build trust among the employees of the organisation. Trust can be built among the employees by setting, enforcing and reinforcing the expectations of behaviours along with the staff by rewarding their behaviour that is desired and exiting perpetrators. Integrity is considered as one of the significant value that should be present in the employees that are hired in the organisation as it is main focus of the employers (Barrett, 2018). Integrity is known as the trademark for the person that shows moral as well as ethical principles at work that are sound.

\section{Impact of flexible culture on organizational integrity and diversity}

In accordance to the study that has been conducted by Mbeba (2014) a flexible culture when integrated in an organisation is considered to enhance the empowerment of the employees where the shift of power is from the upper management to the lower management. It is also important to express that employees start to feel quite relaxed and less stressed when they come across a culture that is entirely based upon principles of flexibility (Hunt, Layton \& Prince, 2015). An assumption has been made that the flexible culture allows to develop an easy mode of communication between the employees and the managers and gives the ease to make important decisions. As per the study that has been conducted by Otwori \& Juma (2015) it is important to share that when a flexible culture is followed in an organisation there is a chance that that it could have an impact upon the integrity. The reason being is that when flexibility is followed, the employees enjoy their jobs and become more honest and committed to the organisational goals higher.

\section{Organisational Integrity in Pakistani Industrial Sector}

As per the study the study that has been conducted by Adeyeye et al (2015) there is a need to imply that integrity in the organisation often refers to ethical practices that are occurring in an organisation. It is important to contribute to the aspect that when organisations follow integrity they are likely considered to be related to the type of ethical leadership and management. In the case of Pakistan which has been discussed in the study that has been conducted by Faisal \& Jafri (2017) it is important to deliberate that organisations in the country do become victims of internal corruption.

\section{Research Gap}

In accordance to the study that has been conducted by Choi, Hong \& Lee (2018) it is important to clarify that one of the research gap that has been identified is the difference in wages between the male and the female employees. The difference in the pay scale between the two genders is considered to be a sophisticated gap that the research can deliberately overcome. Another gap that has been identified is the lack of studies that have occurred with regards to the topic which have resulted in the lack of empirical findings for the study (Rohwerder ,2017). It is also important to specify that the since little research has been done so there is a smaller number of empirical findings for the study. This research has tried to identify the impact of 
diversity in organisational integrity that exist in the industrial sector. Moreover, there is also a reason imply that in accordance to the study that has been conducted by Cho, Kim \& Mor Barak (2017) that there are a few studies that discuss of the gender diversity.

\section{THEORETICAL FRAMWORK}

There are several theories that are related to the diversity management and organisational integrity. The theory that is be applied on this study is social learning theory which is considered as the process of learning and linked with the social behaviour. There are several new behaviours that are proposed in this theory that are acquired by the imitation and observation. As per this theory it is analysed that the people engage with some particular activity due to their association with the people engaged in that activity.

\section{RESEARCH MODEL}

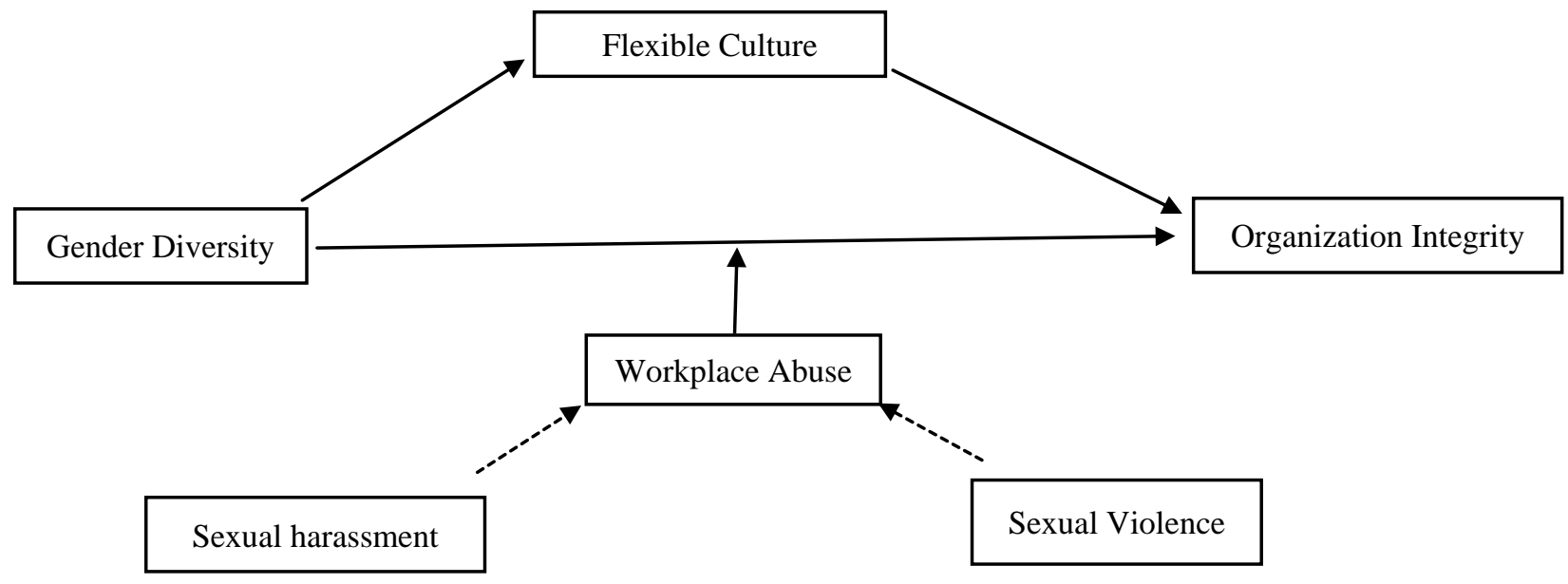

Figure 1: Conceptual model

The above figure 1 is a representation of the conceptual model of the research and the relationships between the factors that have been chosen for the study. There is a need to imply that diversity is considered as the independent variable of the study which is likely going to impact the organisational integrity in the Pakistani industrial sector. There are other mediating variables that have been chosen in the study for its analysis.

H1. The above table illustrates the testing of the hypothesis statements in which it determines as the developed hypothesis has been rejected or accepted. The first hypothesis of the study was based on the diversity and organisational integrity having a significant relationship.

H2. On the basis of the results, the second hypothesis has been accepted where flexible culture mediates the relationship between diversity and organisational integrity.

H3. The third hypothesis, it examines the significant influence of diversity on flexible culture. Similar to the second hypothesis, the regression tool has been applied through Smart PLS where it has been found that diversity has a positive impact on flexible culture. Therefore, on the basis of the results, the third hypothesis has been accepted.

H4. There is a significant influence on the flexible culture on the organisational integrity. The results can be observed in the direct effect section in which it has been found that the flexible culture positively influence on the organisational integrity.

H5. The moderating effect has been found that have insignificant between the two variables diversity and organisational integrity. Diversity fatigue does not have a moderating effect between diversity and organisational integrity.

H6. Female supervision does not have a significant relationship between diversity and organisational integrity. However, direct effect is found with the help of MGA analysis of the female supervision on organisational integrity which was negative as well.

H7. The moderating effects of work place abuse on diversity and organisational integrity. With respect to the results the workplace abuse (sexual harassment, sexual violence) is found to have insignificant affect to diversity and organisational integrity. 


\section{METHODOLOGY}

In the current study, the researcher has followed the deductive research approach. With reference to the findings of Hardwick (2016), a deductive approach by its names deduces and utilise the existence knowledge in order to further test the existing knowledge from different perspective. The study that is the impact of diversity on organisational integrity has already been investigated from prior academics. Therefore, it is justified to say that the phenomenon has already been investigated prudently. Nonetheless, in the current study, the researcher has planned to investigate the research phenomenon from the Pakistani industrial sector perspective. Therefore, the use of the deductive research approach is justified as the researcher has utilised the existing knowledge for the purpose of developing research hypothesis and that have been tested by means of statistical measures

\section{RESEARCH DESIGN}

In this research study quantitative research design has fallowed that to attain the key objectives of this study. The main rationale behind using quantitative method is linked with the objective nature of the research (Roller \& Lavrakas, 2015). Knowing the fact that this study requires more statistical interpretation to determine the actual impact of diversity on organisation integrity in the context of industrial sector of Pakistan; therefore, researcher has opted to incorporate quantitative research design in this study (Schoonenboom \& Johnson, 2017). We used existed questionnaire, and the simple random sampling technique was used in this research. Also, the Structural equation model (SEM) /PLS software was used to analyse the data collected.

\section{Data Collection Method}

To accomplish the key aim of this study, researcher has utilised primary data collection methods to gather most relevant information related to the research topic (Palinkas et al., 2015). The main purpose behind choosing primary data collection method is associated with the main rational of this study, which is to come up with new findings and make useful contribution in the existing literature. By following primary data collection methods, researcher has conducted interviews from relevant personnel's so that most relevant information can be gathered. This has allowed the researcher to gain useful insights about the research topic, and in accomplishing the main aim of this research. Through survey method I distribute the questionnaires to collect the data.

\section{Sampling Technique}

The main reason behind choosing simple random sampling method for this study is because of the simplicity of this method (Glaser \& Strauss, 2017). Moreover, this sampling technique also allow the researcher to choose sample from large population in a fair way, by creating an equal opportunity for each member of the population to get selected for the study. The sample size for this study has been 234, which involves different workers and women's leaders who are working in PASHA association.

\section{Data Analysis Technique}

Knowing the fact that this study is completely based on quantitative research design, therefore, researcher in this study has followed different statistical techniques to understand the collected numeric data (Leavy, 2017). Moreover, as this study involves mediating and moderating variables along with independent and dependent variables, therefore researcher in this study has utilised Structural equation model (SEM) and Meta Regression Analysis (MRA) for achieving the main objectives of this research. For the variable of flexible culture, researcher has followed Structural equation model, whereas for female superior variable researcher has followed Meta regression analysis. The equation for SEM is presented below:

\section{PLS-SEM, STRUCTURAL EQUATION MODEL-PATH ANALYSIS}

The following figure no 2 is the structural equation modelling (SEM) which is deemed as an essential multivariate statistical analysis technique preferably uses to evaluate the structural relationship. The findings of Model (2012), suggested that the technique forms with the blend of multiple regression analysis and factor analysis. In addition to this, the technique is considered an important technique in terms of analysing the relationship between the measured variables and latent constructs. The following is the path analysis for the developed structural equation model which is also being bifurcated into specific segments in the form of direct effect, specific indirect effect, total direct effect and multi-group analysis. With reference to the findings of Ulrich (2018), the threshold for the probability values of t-statistics is considered to be $5 \%$ or 0.05 . Meanwhile, the value for path coefficient is also essential to consider while determining whether the impact is negative or positive. In this sense, it can be articulated that the p-value along with the path-coefficient value helps in determining whether or what nature of impact of one variable is observed on the other variables.

Reliability of different factors was assessed using Smart PLS software for the equivalent factor loadings. A value of 0.45 has been used as the minimum factor loading for sub-factors, as suggested by Comrey (1973). In this study, Hulland (1999) has accepted the sub-factors loading measurements of above 0.50 as suggested. The sub-factors of dimension which subsidized the 
smallest to boost the model fit, the latent constructs were then removed from the model dimension. The resulting final path model Figure 2 is the result for further analysis after the dropouts.

\section{DATA ANALYSIS}

\section{Demographic Analysis}

Demographic analysis has been conducted in order to identify how many respondents have been male and female, their age, education and work experience. Following is the analysis and interpretation of frequencies of demographic questions of the study: The displayed figures of the table show that $67.7 \%$ respondents have been male while $32.4 \%$ of all the respondents have been female. Majority of the respondent were male as 173 respondents were male while 83 were female out of the 256 respondents.

Table 1: Gender details of sample

\begin{tabular}{ccccc}
\hline & Frequency & Percent & Valid Percent & Cumulative Percent \\
\hline Valid Male & 173 & 67.6 & 67.6 & 67.6 \\
\hline Female & 83 & 32.4 & 32.4 & 100.0 \\
\hline Total & 256 & 100.0 & 100.0 & \\
\hline
\end{tabular}

The lack of female respondent is due to the lack of female employees in the industrial sector. Women are mostly secondary school or high school pass outs as the ministry of education states that the ratio between male and female in middle school is $57 \%$ and $47 \%$ and this gap increases with the increase in the level of education. In secondary schools, the ratio is seen as 58\% male and $42 \%$ female whereas, the gap further widens at intermediate and university levels. Thus, when women do not have required qualifications, they cannot get high in position.

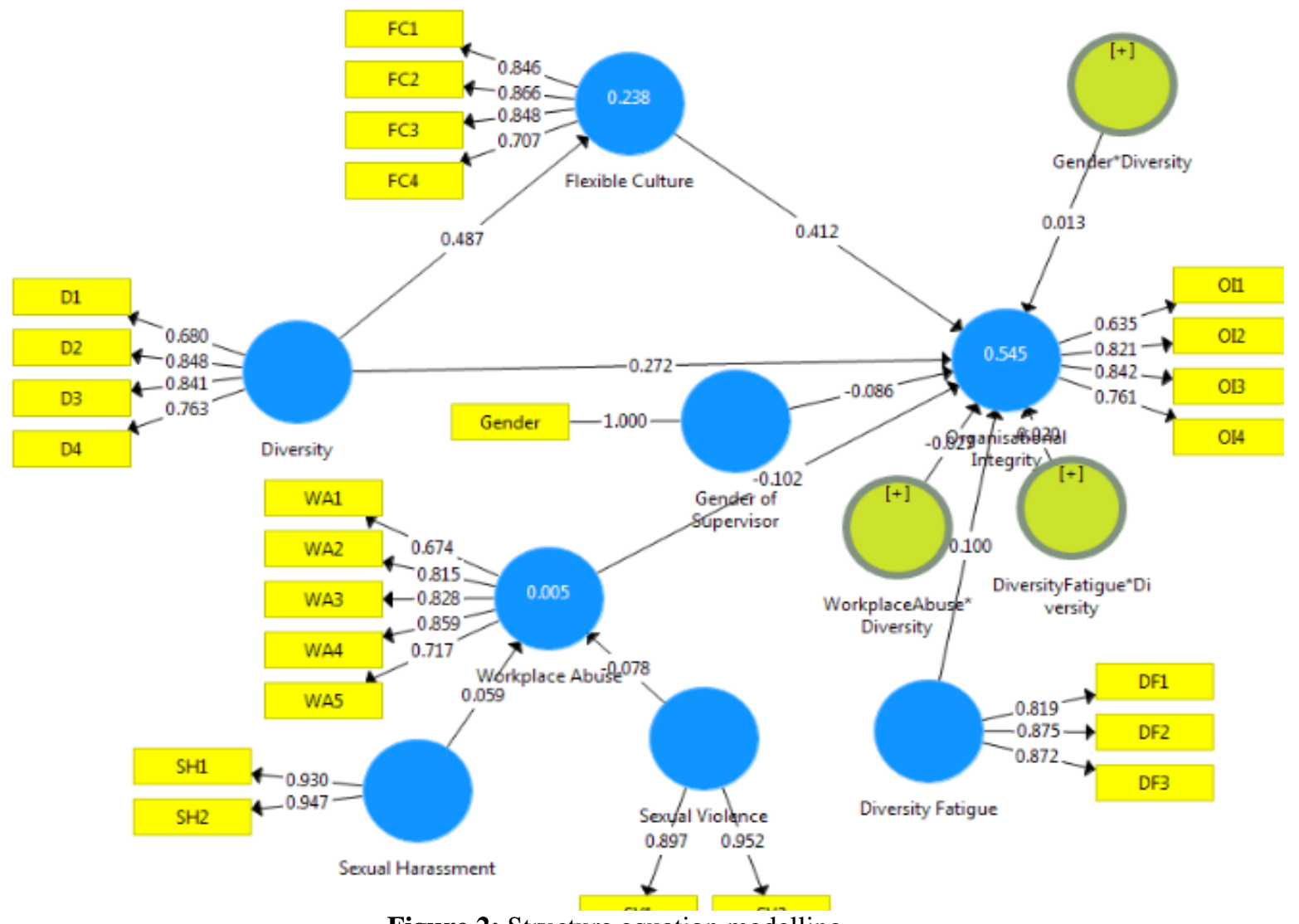

Figure 2: Structure equation modelling

The figures of the table 2 show that $5.1 \%$ had age less than 20 years while $35.9 \%$ have found to be between 21 and 25 years old. $32.8 \%$ of the entire sample population were found to be between 26 and 30 years whereas $15.2 \%$ have been between 31 and 35 years. 
Table 2: Age characteristics of sample

\begin{tabular}{cccccc}
\hline & Frequency & Percent & Valid Percent & Cumulative Percent \\
\hline Valid & Less than 20 years & 13 & 5.1 & 5.1 & 5.1 \\
\hline 21-25 years & 92 & 35.9 & 35.9 & 41.0 \\
\hline 26-30 years & 84 & 32.8 & 32.8 & 73.8 \\
\hline 31-35 years & 39 & 15.2 & 15.2 & 89.1 \\
\hline 36 years and above & 28 & 10.9 & 10.9 & 100.0 \\
\hline Total & 256 & 100.0 & & \\
\hline
\end{tabular}

Lastly, 28\% of the respondents have been 36 years and more than 36 years old. It was necessary to focus on youth of the country because if the more respondents were below 20 than it can produce biased results as most of teenagers in Pakistan are dependent on their parents. Almost 69\% of the respondents are aged between 21 and 30. The reason of such a massive number in this age bracket is that individuals complete their education (mostly graduation and post-graduation) and are looking for opportunities to kick start and develop their careers. The rest of $31 \%$ represents people that pursue higher education or start business on their own in Pakistan or are part of family businesses.

Table 3: Educational details of sample

\begin{tabular}{cccccc}
\hline & & Frequency & Percent & Valid Percent & Cumulative Percent \\
\hline Valid & Intermediate & 5 & 2.0 & 2.0 & 2.0 \\
\hline Bachelors & 104 & 40.6 & 40.6 & 42.6 \\
\hline Masters & 72 & 28.1 & 28.1 & 70.7 \\
\hline PhD & 45 & 17.6 & 17.6 & 88.3 \\
\hline Others & 30 & 11.7 & 11.7 & 100.0 \\
\hline Total & 256 & 100.0 & 100.0 & \\
\hline
\end{tabular}

The table given ahead shows the number of respondents as per their education level. The figures of the table show that $2 \%$ of all the population members had attained education till intermediate level whereas $40 \%$ have attained education level of bachelors. In addition to this, $28.1 \%$ of all the respondents have attained education till master's level and $17.6 \%$ have reached to $\mathrm{PhD}$ level of education. The remaining respondents making up to $11.7 \%$ of the whole sample population has chosen others as a response to their question.

Table 4: Work experience details of sample

\begin{tabular}{ccccc}
\hline & Frequency & Percent & Valid Percent & Cumulative Percent \\
\hline Valid & & & \\
\hline Less than 5 years & 150 & 48.6 & 58.6 & 58.6 \\
\hline 5-10 years & 84 & 32.8 & 32.8 & 91.4 \\
\hline More than 10 years & 22 & 8.6 & 8.6 & 100.0 \\
\hline Total & 256 & 100.0 & 100.0 & \\
\hline
\end{tabular}

The table given ahead shows the number of respondents as per their work experience. The figures of the table show that $58.6 \%$ of all the sample population has found to have less than 5 years of experience whereas $32.8 \%$ have found to have 5 to 10 years of work experience. The remaining respondents were making up to $8.6 \%$ of the whole sample population have more than 10 years of work experience. The table demonstrates that the ratio of young people in industrial sector is high because most of the respondents were having less than 5 years of industry experience. However, this also tends to denote that young population is involved in professional and industrial fields which show that the future of Pakistan is in safe hands.

\section{RESULT AND FINDING}

According to the results derived from the research, it is clear from the first hypothesis that gender diversity is important to boost up the work efficiency and integrity of the organisation. However, the trend seems to have not been identified by organisations in Pakistan since most of the organisations tend to discriminate between male and female employees showing more emphasis towards male employees who are thought of being more hard-working and dedicated towards their job. From the results of study, it can be suggested that employers in Pakistan should diversity their workforce and also look to hire female candidates for the same position as male candidates since it would increase the work efficiency and integrity within an organisation as women tend to work more or equally passionately in their respective fields similar to men.

It can be stated that rigid cultures were followed in traditional times where employees were satisfied with the culture. However, the dynamics have been changing and the workforce demands flexible culture as per their convenience which not only satisfies the employees but also improves productivity, efficiency and integrity within an organisation. Thus, organisations should provide flexible work environment and culture to employees in order to ensure integrity and diversity within an organisation. 
Women also tend to work efficiently within flexible working environments so organisations should provide flexible culture to all genders alike.

Gender diversity is also necessary for the organisation because the fourth hypothesis was accepted which states that flexible culture has significant influence on the organisational integrity. It can be illustrated that having diverse minds in a group of employees tend to bring novel and unique ideas and solutions to problems therefore can benefit the management in the decision-making process. It is therefore recommended to organisations that flexible workplace environment and culture should be promoted by management as it tends to positively contribute towards organisational integrity. At managerial level, it is beneficial to have a female supervisor as females working within a company might not feel comfortable to interact with a male supervisor due to culture of Pakistan and thus, are more comfortable with female supervisors. Thus, the organisations are recommended to encourage females to apply for executive positions in the organisation in order to increase the integrity at workplace. This can also lead to decline in harassment cases as females are considered inferior and this mind-set can be changed by having women at an authoritative position within the organisation.

\section{DISCUSSION AND ANALYSIS}

With respect to the aim of the study, it mainly emphasizes in analysing the influence of diversity on the organisational integrity from the context of Pakistani Industrial sector. For achieving the key aim of the study, there are mainly three objectives that have been formulated. The first objective that has been established mainly seeks to determine whether an increased gender particularly woman representation in the Pakistan industry can lead towards the improvement in the organisational integrity. While referring to the objective, it has been achieved through conducting questionnaire survey and deploying an appropriate survey for achieving the objective. Therefore, the multi-group analysis is incorporated for determining whether the female employees influences on the organisational integrity in the Pakistan industry. The results of the multi-group analysis have revealed that the diversity has significant influence on organisational integrity. Therefore, this has led towards achieving the objective in which it has been determined that increased gender particular woman in the Pakistani industry positively influences on the organisational integrity.

The second particular objective has been achieved through analysing the studies and literature for identifies as how the female leaders has an association between diversity and organisation integrity. The last objective of the study was reflected towards understanding the importance of work place diversity for increasing the organisational performance. This particular objective pertained with examining and investigating literature while also conducting research on the context of Pakistani industry.

\section{Reliability and Convergent Validity Testing Confirmatory Analysis}

Following the initial assessment for demographics and correlation analysis, the confirmatory factor analysis has now proceeded. Confirmatory factor analysis (CFA) is assumed as an effective form of factor analysis that helps in evaluating the measures or indicators involved in the study. With reference to the findings of Brown (2012), CFA is an essential factor analysis tool that helps in determining what indicators of constructs are relevant. Here it becomes important to mention that CFA is mainly bifurcated into assessment. One is concerned with testing the reliability and convergent validity. The other is concerned with the assessment of discriminant validity. Specific to the assessment of the reliability and convergent validity testing, the reliability is determined through the Cronbach Alpha and Composite reliability while the convergent validity is determined through average variance extracted (AVE).

Table 5: Reliability and Convergent Validity Testing

\begin{tabular}{|c|c|c|c|c|c|}
\hline Variables & Indicators & Factor Loading & $\begin{array}{l}\text { Cronbach's } \\
\text { Alpha }\end{array}$ & $\begin{array}{l}\text { Composite } \\
\text { Reliability }\end{array}$ & $\begin{array}{l}\text { Average Variance } \\
\text { Extracted (AVE) }\end{array}$ \\
\hline \multirow{4}{*}{ Diversity } & D1 & 0.680 & 0.790 & 0.865 & 0.618 \\
\hline & $\mathrm{D} 2$ & 0.848 & & & \\
\hline & D3 & 0.841 & & & \\
\hline & D4 & 0.763 & & & \\
\hline \multirow[t]{4}{*}{ Flexible Culture } & FC1 & 0.846 & 0.835 & 0.890 & 0.671 \\
\hline & $\mathrm{FC} 2$ & 0.866 & & & \\
\hline & FC3 & 0.848 & & & \\
\hline & FC4 & 0.707 & & & \\
\hline \multirow[t]{4}{*}{ Organisational Integrity } & OI1 & 0.635 & 0.766 & 0.851 & 0.591 \\
\hline & $\mathrm{OI} 2$ & 0.821 & & & \\
\hline & OI3 & 0.842 & & & \\
\hline & OI4 & 0.761 & & & \\
\hline \multirow[t]{2}{*}{ Workplace Abuse } & WA1 & 0.674 & 0.839 & 0.886 & 0.611 \\
\hline & WA2 & 0.815 & & & \\
\hline
\end{tabular}




\begin{aligned} & \hline WA3 0.828 \\ & \hline WA4 0.859 \\ & \hline WA5 0.717 \\ & \hline\end{aligned}

The aforementioned table represents the reliability and convergent testing of all the indicators involved in all the seven constructs of the study. As already discussed, the threshold value for the factor loading is considered as 0.6 therefore, if all the indicators appear at 0.6 or greater than 0.6 , then it can have accepted and suggests the indicator is extracting sufficient variance from the construct. While referring to the above-mentioned table, it is justified to say that all the indicators extract sufficient variance from their construct because the factors loadings obtained from Smart PLS are above 0.6. Furthermore, in terms of determining the reliability of each construct, the reference is made with the Cronbach alpha and composite reliability. As already discussed, in order to claim the variables are reliable, the value for Cronbach alpha and composite reliability must be greater than the 0.7. On the basis of the aforementioned table, it is justified to say that all the variables are reliable as the values of all the indicator have appeared as greater than 0.7. The last measure in the above-mentioned table is AVE. With reference to the findings of Valentini (2016), the threshold for AVE is considered as AVE and the indicators whose values appeared greater than 0.5 , then it is suggested that the construct fulfil the criterion of convergent validity.

\section{Discriminant Validity (HTMT Ratio)}

Other than convergent validity, it is also necessary to examine the discriminant validity of the constructs which in this study has been tested with HTMT ratio. The results have been presented in the table as follows:

Table 6: Discriminant Validity

\begin{tabular}{lcccllll}
\hline & Diversity & $\begin{array}{l}\text { Diversity } \\
\text { Fatigue }\end{array}$ & $\begin{array}{l}\text { Flexible } \\
\text { Culture }\end{array}$ & $\begin{array}{l}\text { Gender of } \\
\text { Supervisor }\end{array}$ & $\begin{array}{l}\text { Organisational } \\
\text { Integrity }\end{array}$ & $\begin{array}{l}\text { Sexual } \\
\text { Harassment }\end{array}$ & $\begin{array}{l}\text { Sexual } \\
\text { Violence }\end{array}$ \\
\hline $\begin{array}{l}\text { Diversity } \\
\text { Fatigue }\end{array}$ & 0.5900 & & & & & \\
\hline $\begin{array}{l}\text { Flexible } \\
\text { Culture }\end{array}$ & 0.5872 & 0.7141 & & & & \\
\hline $\begin{array}{l}\text { Gender of } \\
\text { Supervisor }\end{array}$ & 0.1224 & 0.0302 & 0.1310 & & & \\
\hline $\begin{array}{l}\text { Organisational } \\
\text { Integrity }\end{array}$ & 0.1017 & 0.6684 & 0.8118 & 0.8151 & & \\
\hline $\begin{array}{l}\text { Sexual } \\
\text { Harassment }\end{array}$ & 0.0968 & 0.0387 & 0.0782 & 0.0225 & 0.0902 & \\
\hline $\begin{array}{l}\text { Sexual } \\
\text { Violence }\end{array}$ & 0.0629 & 0.0497 & 0.0484 & 0.0389 & 0.0674 & 0.5911 & \\
\hline $\begin{array}{l}\text { Workplace } \\
\text { Abuse }\end{array}$ & 0.0110 & 0.0150 & 0.0180 & 0.0210 & 0.0280 & 0.0309 & 0.0644 \\
\hline
\end{tabular}

The aforementioned table is concerned with discriminant validity. As per the findings of Henseler (2016), the discriminant validity is mainly examined by means of HTMT ratio whose threshold value is considered to be 0.85 . The researcher has further stretched that the value for HTMT ratio must be lesser than 0.85 in order to claim the values are valid and distinct. In the aforementioned table, the values for all the HTMT ratios have appeared as lesser than 0.85 . This suggests that all the constructs are distinct and valid. The highest value has been found as 0.8151 between the ratios workplace abuse and diversity fatigue. Conclusively, it can be suggested that all the variables are still distinct and valid.

\section{Structural Equation Model- Path Analysis}

The following is the structural equation modelling (SEM) which is deemed as an essential multivariate statistical analysis technique preferably uses to evaluate the structural relationship. The findings of Model (2012), suggested that the technique forms with the blend of multiple regression analysis and factor analysis. In addition to this, the technique is considered an important technique in terms of analysing the relationship between the measured variables and latent constructs. The following is the path analysis for the developed structural equation model which is also being bifurcated into specific segments in the form of direct effect, specific indirect effect, total direct effect and multi-group analysis. With reference to the findings of Ulrich (2018), the threshold for the probability values of t-statistics is considered to be $5 \%$ or 0.05 . Meanwhile, the value for path coefficient is also essential to consider while determining whether the impact is negative or positive. In this sense, it can be articulated that the p-value along with the path-coefficient value helps in determining whether or what nature of impact of one variable is observed on the other variables. 
The tool that has been incorporated for testing the first hypothesis is through the correlation analysis. On the basis of the results, the p-value is 0.000 . it has been found that diversity has a significant and positive association with the organisation integrity. Therefore, the first hypothesis has been accepted whereas its null hypothesis has been rejected. Several studies have supported the hypothesis such as Barett (2018) highlights that organisation with high level of diversity improves the integrity of organisation as these components are inter-related with each other.

While referring to the second hypothesis, it was assumed that the flexible culture mediates the relationship between diversity and organisational integrity. The regression analysis has been conducted in which flexible culture mediating effects has been measured between diversity and organisational culture. The results of the analysis indicate that the flexible culture significantly mediates between diversity and organisational integrity. On the basis of the result as the p-value is 0.000 , the second hypothesis has been accepted where flexible culture mediates the relationship between diversity and organisational integrity.

Table 7: Path Coefficients along with their bootstrap values and ' $T$ ' Values

\begin{tabular}{|c|c|c|c|c|c|c|}
\hline $\mathbf{H}$ & Path & $\mathbf{B}$ & St.D & T-values & P Values & Remark \\
\hline H1 & Gender diversity $\rightarrow>$ organizational integrity. & 0.304 & 0.046 & 6.623 & 0.000 & Supported \\
\hline $\mathrm{H} 2$ & $\begin{array}{l}\text { Flexible culture ->gender diversity ->organizational } \\
\text { integrity }\end{array}$ & 0.321 & 0.045 & 7.183 & 0.000 & Supported \\
\hline $\mathrm{H} 3$ & gender diversity $->$ flexible culture & 0.246 & 0.049 & 5.027 & 0.000 & Supported \\
\hline $\mathrm{H} 4$ & Flexible culture -> organizational integrity. & 0.290 & 0.045 & 6.474 & 0.000 & Supported \\
\hline H5 & $\begin{array}{lllll}\begin{array}{l}\text { Diversity fatigue -> } \\
\text { organizational integrity }\end{array} & \text { gender } & \text { diversity } & \text {-> } \\
\end{array}$ & 0.115 & 0.124 & 0.294 & 0.769 & Rejected \\
\hline H6 & $\begin{array}{llll}\begin{array}{l}\text { Female supervision } \\
\text { organizational integrity }\end{array} & \text {->gender } & \text { diversity } & \text {-> } \\
\end{array}$ & 0.037 & 0.036 & 1.314 & 0.753 & Rejected \\
\hline H7 & $\begin{array}{l}\text { Work place abuse (sexual harassment, sexual } \\
\text { violence)-> gender diversity } \rightarrow \text { organizational } \\
\text { integrity }\end{array}$ & 0.030 & 0.014 & 0.373 & 0.709 & Rejected \\
\hline
\end{tabular}

With respect to the third hypothesis, it examines the significant influence of diversity on flexible culture. Similar to the second hypothesis, the regression tool has been applied through Smart PLS where it has been found that diversity has a positive impact on flexible culture. Therefore, on the basis of the results with the p-value is 0.000 the third hypothesis has been accepted whereas its null hypothesis has been rejected.

While referring to the fourth hypothesis, it has been assumed that there is a significant influence on the flexible culture on the organisational integrity. The results can be observed in the direct effect section in which it has been found that the flexible culture positively influence on the organisational integrity. Therefore, with the p-value of 0.000 the alternative hypothesis has been accepted whereas the null hypothesis is rejected. The fifth hypothesis is emphasized in measuring the moderating effect of diversity fatigue between diversity and organisational integrity. The moderating effect has been found with the p-value of 0.769 which shows that have insignificant between the two variables diversity and organisational integrity. Thus, the null hypothesis is accepted in which the diversity fatigue does not have a moderating effect between diversity and organisational integrity.

The sixth hypothesis of the study is based on the moderating variable female supervision which has a significant relationship between diversity and organisational integrity. On the basis of the results, it is found that female supervision does not have a significant relationship between diversity and organisational integrity. Therefore, the sixth hypothesis of the study has been rejected as female supervision does not have a significant relationship between diversity and organisational integrity. However, direct effect is found with the help of MGA analysis of the female supervision on organisational integrity which was negative as well. The last and seventh hypothesis of the study explores the moderating effects of work place abuse on diversity and organisational integrity. With respect to the results with the p-value of 0.709 , the workplace abuse is found to have insignificant affect to diversity and organisational integrity. Therefore, the last null hypothesis is accepted whereas the alternative hypothesis is rejected.

\section{CONCLUSION}

There are three different research objectives which had been decided on in the initial planning phases of this research. These three research objectives are to find out whether an increased gender (w.r.t women) representation in the Pakistani industry lead to an improvement in organisational integrity, to investigate how the incidence of female leaders influences the association between diversity and organisational integrity, and to know whether work place diversity has an important effect on increase in organisational performance (Rasli, 2018; Sattarm, 2019). As many as seven different hypotheses have been statistically tested 
in order to meet the research objectives. Out of these seven-research hypotheses, four have been accepted while 3 have been rejected.

The first hypothesis pertains to the concept of diversity and organisational integrity significantly related with each other. This hypothesis was edited by the correlation analysis. The statistical tests point out that this hypothesis must be accepted due to the reason that there is a significant positive relationship of organisational integrity with the concept of diversity. The second hypothesis stated that flexible culture practically mediates the relationship between organisational integrity and diversity at the workplace. In order to statistically validate this hypothesis, regression analysis was conducted. Results and the findings present the idea that there is a positive evidence as to the mediating role of flexible organisational culture between the variables of organisation integrity and diversity at the workplace (Masschelein, 2015; Morgan, 2016; Nichols, 2015).

The third hypothesis stated that there is a significant influence of diversity on physical culture. Again, the regression analysis was used in order to validate and statistical verify the hypothesis. This time the regression analysis for supplied through smart PLS and a positive result was obtained in that there is a positive influence on flexible culture (Menzel, 2016). Hence the third hypothesis was also accepted. The fourth hypothesis stated that there is a significant influence of flexible culture on the organisational integrity. The direct effect section has particularly discussed this hypothesis and has found a significant positive influence of flexible culture on the construct of organisation integrity (Kelly and Kelly ,2017). The fifth hypothesis assesses the moderating influence of the construct of diversity fatigue between the constructs of organisational integrity and diversity. This moderating effect was found to be insignificant and hence the hypothesis was rejected. The sixth hypothesis stated that there exists a moderating variable of female supervision which has a significant influence on the relationship between organisation integrity and diversity at workplace. The results and the findings of this study reveal that this moderating effect is insignificant which automatically rejects the null hypothesis under consideration. The final hypothesis which is the seventh hypothesis of this study states that there exists a moderating influence of workplace abuse on the relationship between diversity and organisational integrity. Since this moderating effect turns out to be insignificant in the context of the Pakistani industry, this particular hypothesis has also been rejected.

\section{LIMITIONS AND STUDY FORWARD}

There are several limitations that are linked with this study, and which has been faced by researcher during the completion of this research. According to Greener (2018), no research study can be entirely inclusive from all aspects; thus it is essential to list down the key limitations of the research to portray the transparency of the study. In the context of this study, time constraint was one of the key limitations that researcher has faced during the completion of this research, which as a result has limit the scope of study in terms of limited sample size, and the absenteeism of qualitative research design.

As this research is conducted only in Pakistan so the results of this research are also restricted to Pakistan. In future, same research can be conducted in other countries. In this way, the results could be different in different countries due to the tradition and perspective of their countrymen and because of different of economic situation, political stability and terrorism etc. Secondly, same research could be conducted on different sectors as this research was particular to the industrial sector only. In future, the researchers are recommended to conduct research on service, especially financial services sector, because it has been seen that females are encouraged to work in the financial sector with banks being the top employers of females. Thus, it would lead to know whether the results differ from industry to industry or the culture and tradition of a country have more impact on diversity and integrity within an organisation.

\section{ACKNOWLEDGMENT}

I am so thankful of my supervisor and dean of the faculty of economic and social \& applied science for supporting my entire study. This study conducted by using my supervisor zest and my own money to expose the finding of this research which will be read by readers around the world and may become the lesson learned for further researcher and students.

\section{AUTHORS CONTRIBUTION}

The co-author did a critical revision of the article. Co-authors provided critical feedback and helped shape the research, analysis and manuscript and finally approval of the version for publication.

\section{REFERENCE}

1. Abbas, Z. (2014). Identification of factors and their impact on employees' training and organizational performance in Pakistan. Kasbit journal of management \& social science, 7(1), 93-109.

2. Adeyeye, O. J., Adeniji, A. A., Osinbanjo, A. O., \& Oludayo, O. O. (2015). Effects of workplace ethics on employees and organisational productivity in Nigeria. International Conference on African Development Issues (CU-ICADI) 2015: Social and Economic Models for Development Track.

3. ANJORIN, R. and Jansari, A., (2018). Managing Cultural Diversity at Workplace. www.divaportal.org(diva2:1217258) 
4. Ashraf, J. (2017). Public sector appointments, political influence and performance: perceptions of the situation in Pakistan. Asia Pacific Journal of Public Administration, 39(3), 211-216. https://doi.org/10.1080/23276665.2017.1365467

5. Barger, L.K., Runyon, M.S., Renn, M.L., Moore, C.G., Weiss, P.M., Condle, J.P., Flickinger, K.L., Divecha, A.A., Coppler, P.J., Sequeira, D.J. and Lang, E.S., (2018). Effect of fatigue training on safety, fatigue, and sleep in emergency medical services personnel and other shift workers: a systematic review and meta-analysis. Prehospital Emergency Care, 22(sup1), pp.58-68. https://doi.org/10.1080/10903127.2017.1362087

6. Barrett, R. (2018). Influence of self-control, risk-taking, manipulation and integrity on organisational citizenship behaviour (Doctoral dissertation, Stellenbosch: Stellenbosch University).

7. Brown, T.A. and Moore, M.T., 2012. Confirmatory factor analysis. Handbook of structural equation modelling, pp.361-379.

8. Cho, S., Kim, A., \& Mor Barak, M. E. (2017). Does diversity matter? Exploring workforce diversity, diversity management, and organisational performance in social enterprises. Asian Social Work and Policy Review, 11(3), 193204. https://doi.org/10.1111/aswp.12125

9. Choi, H., Hong, S., \& Lee, J. W. (2018). Does Increasing Gender Representativeness and Diversity Improve Organisational Integrity?. Public Personnel Management, 47(1), 73-92. https://doi.org/10.1177/0091026017738539

10. Connon, S. and Corneliussen, K., 2016, September. The Use of Well Integrity Management Systems \& Software to Increase Organisational Understanding. In SPE Intelligent Energy International Conference and Exhibition. Society of Petroleum Engineers. https://doi.org/10.2118/181021-MS

11. Cropanzano, R., Anthony, E.L., Daniels, S.R. and Hall, A.V., (2017). Social exchange theory: A critical review with theoretical remedies. Academy of Management Annals, 11(1), pp.479-516. https://doi.org/10.5465/annals.2015.0099

12. Ellis, K. M., \& Keys, P. Y. (2015). Workforce diversity and shareholder value: a multi-level perspective. Review of Quantitative Finance and Accounting, 44(2), 191-212. https://doi.org/10.1007/s11156-013-0403-7

13. Faisal, F., \& Jafri, A. R. (2017). Corruption as a source of failure of good governance and management in Pakistan: Proposed remedial measures. Journal of the Punjab University Historical Society (JPUHS), 30(1), 57-75.

14. Gardiner, S., Parry, J. and Robinson, S., (2017). Integrity and the corruption debate in sport: where is the integrity?. European sport management quarterly, 17(1), pp.6-23. https://doi.org/10.1080/16184742.2016.1259246

15. Greener, S., 2018. Research limitations: the need for honesty and common sense. Interactive Learning Environments, 26(5), pp.567-568. https://doi.org/10.1080/10494820.2018.1486785

16. Glaser, B. G., \& Strauss, A. L. (2017). Theoretical sampling. In Sociological methods (pp. 105-114). Routledge. https://doi.org/10.4324/9781315129945-10

17. Hardwick, S.W., (2016). Case study approach. International Encyclopedia of Geography: People, the Earth, Environment and Technology, pp.1-6. https://doi.org/10.1002/9781118786352.wbieg0186

18. Henseler, J., Ringle, C.M. and Sarstedt, M., (2015). A new criterion for assessing discriminant validity in variancebased structural equation modeling. Journal of the academy of marketing science, 43(1), pp.115-135. https://doi.org/10.1007/s11747-014-0403-8

19. Hong, S. (2016). Representative bureaucracy, organisational integrity, and citizen coproduction: Does an increase in police ethnic representativeness reduce crime?. Journal of Policy Analysis and Management,35(1), 11-33. https://doi.org/10.1002/pam.21876

20. Hunt, V., Layton, D., \& Prince, S. (2015). Diversity matters. McKinsey \& Company, 1, 15-29.

21. Idrees, R. N., Abbasi, A. S., \& Waqas, M. (2013). Systematic review of literature on workforce diversity in Pakistan. Middle-East Journal of Scientific Research, 17(6), 780-790.

22. Kelly, D. H., \& Kelly, G. P. (2017). Women's education in the third world: An annotated bibliography. Routledge.

23. Kelsey, C. L. (2015). Gender inequality: Empowering women. Journal of Legal Issues and Cases in Business, $3,1$.

24. Khan, A. H., Nawaz, M. M., Aleem, M., \& Hamed, W. (2012). Impact of job satisfaction on employee performance: An empirical study of autonomous Medical Institutions of Pakistan. African Journal of Business Management, 6(7), 2697-2705.

25. Kim, T. and Mullins, L.B., (2016). How does supervisor support and diversity management affect employee participation in work/family policies?. Review of Public Personnel Administration, 36(1), pp.80-105. https://doi.org/10.1177/0734371X14553883

26. Leavy, P., 2017. Research design: Quantitative, qualitative, mixed methods, arts-based, and community-based participatory research approaches. Guilford Publications.

27. Lo, J. (2016). Office Ladies/Factory Women: Life and Work at a Japanese Company: Life and Work at a Japanese Company. Routledge. https://doi.org/10.4324/9781315289298

28. Mak, G. C. (2017). Women, education and development in Asia: Cross-national perspectives. Routledge. https://doi.org/10.4324/9781315143965 
29. Masschelein, S., 2015. How leader alignment of words and deeds affects followers: A meta-analysis of behavioral integrity research. Journal of Business Ethics, 132(4), pp.831-844. https://doi.org/10.1007/s10551-014-2332-3

30. Mbeba, R. D. (2014). Essence of a flexible organisational culture to influence change in the 21st century organisation. Mediterranean Journal of Social Sciences, 5(7), 663. https://doi.org/10.5901/mjss.2014.v5n7p663

31. Menzel, D.C., 2016. Ethics management for public and nonprofit managers: Leading and building organizations of integrity. Routledge. https://doi.org/10.4324/9781315641256

32. Model, M.S.E., (2012). Restructuring and expanding technology acceptance model structural equation model and Bayesian approach. American Journal of Applied Sciences, 9(4), pp.496-504. https://doi.org/10.3844/ajassp.2012.496.504

33. Morgan, K., 2016. What determines ethical behavior in public organizations: Is it rules or leadership? Public Administration Review, 76(6), pp.898-909. https://doi.org/10.1111/puar.12562

34. Nichols, C.M., 2015. Virtuous leadership: Exploring the effects of leader courage and behavioral integrity on leader performance and image. Journal of Business Ethics, 132(2), pp.297-310. https://doi.org/10.1007/s10551-014-2317-2

35. Otwori, N. L., \& Juma, D., (2015). Effect of Organizational Values on Employee Performance a Case of Urban Roads Authority. https://www.semanticscholar.org/ semantic scholar.

36. Palinkas, L. A., Horwitz, S. M., Green, C. A., Wisdom, J. P., Duan, N., \& Hoagwood, K. (2015). Purposeful sampling for qualitative data collection and analysis in mixed method implementation research. Administration and policy in mental health and mental health services research, 42(5), 533-544. https://doi.org/10.1007/s10488-013-0528-y

37. Rasli, A., 2018. Direct and indirect effects of ethical leadership on workplace deviance in public healthcare sector of Pakistan. Journal of Advances in Management Research, 15(4), pp.558-574. https://doi.org/10.1108/JAMR-11-2017$\underline{0109}$

38. Rice, M.F., (2015). Diversity and public administration. https://doi.org/10.4324/9781315705149

39. Rizwan, M., Khan, M. N., Nadeem, B., \& Abbas, Q. (2016). The impact of workforce diversity towards employee performance: Evidence from banking sector of Pakistan. American Journal of Marketing Research, 2(2), 53-60.

40. Rojas, R.R., 2018. Diversity and Workplace Spirituality. In Diversity and Inclusion in the Global Workplace (pp. 81107). Palgrave Macmillan, Cham. https://doi.org/10.1007/978-3-319-54993-4 5

41. Roller, M. R., \& Lavrakas, P. J. (2015). Applied qualitative research design: A total quality framework approach. Guilford Publications.

42. Rohwerder, B. (2017). Impact of diversity and inclusion within organisations.

43. Sarwar, F. and Abbasi, A.S., 2013. An in-depth analysis of women's labor force participation in Pakistan. MiddleEast Journal of Scientific Research, 15(2), pp.208-215.

44. Sattar, S., 2019. The Effects of Despotic Leadership and Sexual Harassment on Emotional Exhaustion of Employees in Health Sector of Pakistan: Moderating Role of Organizational Cynicism. Review of Economics and Development Studies, 5(2), pp.269-280. https://doi.org/10.26710/reads.v5i2.587

45. Schoonenboom, J., \& Johnson, R. B. (2017). How to construct a mixed methods research design. KZfSS Kölner Zeitschrift für Soziologie und Sozialpsychologie, 69(2), 107-131. https://doi.org/10.1007/s11577-017-0454-1

46. Tahir, N., Yousafzai, I. K., Jan, S., \& Hashim, M. (2014). The Impact of Training and Development on Employees Performance and Productivity A case study of United Bank Limited Peshawar City, KPK, Pakistan. International Journal of Academic Research in Business and Social Sciences, 4(4), 86. https://doi.org/10.6007/IJARBSS/v4-i4/756

47. Ulrich, R., Miller, J. and Erdfelder, E., (2018). Effect size estimation from t-statistics in the presence of publication bias. Zeitschrift für Psychologie. https://doi.org/10.1027/2151-2604/a000319

48. Valentini, F. and Damásio, B.F., 2016. Average Variance Extracted and Composite Reliability: Reliability Coefficients/Variancia Media Extraida e Confiabilidade Composta: Indicadores de Precisao. Psicologia: Teoria e Pesquisa, 32(2). https://doi.org/10.1590/0102-3772e322225

49. Van Wagoner, P., Embry, E., Barnes, L.Y., Rivin, J.M., Reed, R., Hekman, D.R., Volpone, S.D. and Johnson, S., (2019). Leveraging Diversity to Enhance Inclusion Efforts for Team Processes and Outcomes. In Academy of Management Proceedings, Vol. 2019, No. 1, p. 15302. Briarcliff Manor, NY 10510: Academy of Management. https://doi.org/10.5465/AMBPP.2019.15302abstract

50. Wahab, H.A. and Jaafar, H.J., 2018. WORKPLACE DIVERSITY: HOW DOES MALAYSIAN LAW PROMOTE PEOPLE WITH DISABILITY? International Journal, 3(9), pp.14 -23. 